\title{
Strategi Peningkatan Objektivitas Hasil Uji Inspeksi Visual Sediaan Injeksi: Review
}

\author{
Deti Dewantisari*, ${ }^{*}$, Ida Musfiroh ${ }^{2}$ \\ ${ }_{1}^{1}$ Program Studi Apoteker, Fakultas Farmasi, Universitas Padjadjaran \\ 2Departemen Analisis Farmasi dan Kimia Medisinal, Fakultas Farmasi, Universitas Padjadjaran \\ *E-mail : detidewantisari@gmail.com
}

(Submit 30/1/2020, Revisi 4/2/2020, Diterima 8/2/2020)

\begin{abstract}
Abstrak
Sediaan injeksi merupakan sediaan steril yang bebas dari kontaminasi pirogenik, endotoksin, partikulat, stabil secara fisika, kimia, dan mikrobiologi, isotonis, dan isohidris. Salah satu faktor penting untuk memastikan sediaan injeksi terbebas dari partikulat adalah inspeksi visual oleh seorang operator, keakuratan dari hasil inspeksi visual ini sangat bergantung kepada ukuran partikel dan pengalaman dari operator Tujuan literature review ini menjelaskan prosedur pelaksanaan inspeksi visual dengan tepat dan tahapan yang dapat dilakukan untuk meningkatkan objektifitas hasil inspeksi, sehingga hasil yang ditetapkan tidak bias. Beberapa metode yang berpengaruh terhadap inspeksi visual ini diantaranya kontras background pengujian, cahaya, pergerakan partikel, waktu dan kecepatan inspeksi, serta jumlah operator. Pembuatan analisis bagan pareto yang cacat, pembuatan persetujuan spesifikasi cacat, evaluasi kinerja inspeksi, hingga sertifikasi operator dapat diterapkan untuk meningkatkan objektifitas dari hasil visual inspeksi. Keputusan hasil inspeksi visual pada akhirnya ditentukan oleh ketelitian, penglihatan dan pengalaman dari seorang operator.
\end{abstract}

Kata kunci : Inspeksi visual, Metode, Operator, Steril.

\section{Outline}

- Pendahuluan

- Metode

- Hasil dan Pembahasan

- Kesimpulan

- Daftar Pustaka

\section{Pendahuluan}

Industri farmasi terus mengalami perkembangan secara cepat, di mana proses produksi obat menjadi lebih kompleks sehingga memungkinkan tingkat produksi yang lebih tinggi dengan bentuk sediaan yang makin beragam. Hal ini berdampak pada peningkatan potensi bahaya dari kualitas produk yang tidak memenuhi spesifikasi, seperti kemasan obat yang tidak konsisten, label yang keliru hingga adanya kontaminasi dalam produk ${ }^{1}$. 
Salah satu bentuk sediaan yang sering digunakan adalah injeksi, menurut Farmakope Indonesia Edisi IV, injeksi umumnya berupa larutan obat dalam air yang bisa diberikan secara intravena dan dikemas dalam wadah $100 \mathrm{~mL}$ atau kurang. Sediaan steril injeksi dapat berupa ampul, ataupun berupa vial. Adapun syarat sediaan steril adalah sterilitas, bebas kontaminasi pirogenik dan endotoksin, bebas partikulat, stabil secara fisika, kimia, dan mikrobiologi, isotonis, dan isohidris².

Inspeksi visual merupakan suatu metode untuk mendeteksi adanya partikulat asing dalam sediaan. Tahapan ini merupakan proses yang paling sulit dalam tahapan proses quality control. Partikulat dalam sediaan dapat dipengaruhi oleh beberapa faktor, baik dalam proses produksi, bahan baku, peralatan yang digunakan, maupun kemasan yang digunakan. Adanya partikulat dalam sediaan injeksi dapat menimbulkan bahaya biologis, bahaya yang dapat ditimbulkan antara lain, menyebabkan luka yang dapat memicu terjadinya infeksi dan inflamasi, menstimulasi respon imun tubuh seperti terjadinya alergi atau anafilaksis, tromboemboli hingga timbulnya granuloma paru dan emboli3.

Adanya partikulat dalam sediaan injeksi akan menjadikan suatu produk dilakukan recall. Pada tahun 2014 terdapat beberapa kasus recall yang diakibatkan oleh adanya partikulat dalam produk injeksi, diantaranya : penarikan secara sukarela yang dilakukan oleh Hospira terhadap 1 lot injeksi Lidokain 1\% karena adanya partikulat berupa rambut manusia, penarikan oleh Baxter terhadap dua lots larutan Dialisis Peritoneal karena adanya partikulat berupa Oxidized stainless steel, garment fiber, PVC, serta penarikan oleh Cubits Pharmaceuticals terhadap lots Cubicin karena adanya partikulat gelas ${ }^{4}$. Pada Tahun 2014, 55 dari total 337 kasus recall disebabkan karena adanya partikel di sediaan parenteral, pada Tahun 2016, terdiri dari 97 laporan recall terhadap produk parenteral yang disebabkan oleh adanya partikel, serta 25 dan 26 kasus recall pada tahun 2017 dan $2018^{5}$.

Pelaksanaan inspeksi visual di industri farmasi umumnya masih menggunakan penglihatan manual dari seorang operator, untuk itu keakuratan dari hasil inspeksi visual ini sangat bergantung kepada ukuran partikel dan pengalaman dari operator ${ }^{6}$. Ukuran partikel yang mungkin ada pada sediaan berukuran 50-200 mikron. Sedangkan, ukuran probabilitas deteksi oleh seorang operator terlatih yang memenuhi syarat hanya 4\% untuk ukuran partikel 50 mikron, meningkat hingga lebih dari 90\% probabilitas deteksinya pada ukuran partikel lebih dari $200 \mu \mathrm{m}^{7}$. Untuk itu, kekurangan penglihatan manusia dalam proses inspeksi harus dipertimbangkan terutama dalam menentukan probabilitas dan kecacatan karena dapat mempengaruhi objektifitas hasil inspeksi visual [8]. Literature review ini bertujuan untuk menjelaskan prosedur pelaksanaan inspeksi visual dengan tepat dan tahapan yang dapat dilakukan untuk meningkatkan objektifitas hasil inspeksi, sehingga hasil yang ditetapkan tidak bias.

\section{Metode}

Metode yang digunakan pada Literature Review ini adalah dengan mengumpulkan data dari beberapa compendial, buku ilmiah dan referensi jurnal ilmiah yang berkaitan dengan inspeksi visual sediaan injeksi. 
Adapun kriteria yang digunakan untuk jurnal ilmiah yaitu jurnal yang telah dipublikasi baik pada jurnal nasional maupun jurnal internasional tahun 2005-2019 yang berhubungan dengan cara pelaksanaan uji inspeksi visual dan tahapan untuk meningkatkan objektivitas hasil uji inspeksi visual. Jumlah referensi yang digunakan dalam literature review ini sebanyak 17 referensi, yang terdiri dari 10 jurnal utama dan 7 referensi pendukung.

\section{Hasil}

Beberapa strategi telah dilakukan untuk meningkatkan objektivitas hasil inspeksi visual sediaan injeksi, berikut beberapa jurnal yang membahas mengenai tahapan atau kegiatan yang dilakukan untuk meningkatkan objektivitas hasil uji inspeksi visual di tabel 1.

Tabel 1 Peningkatan objektivitas hasil inspeksi visual sediaan injeksi

\begin{tabular}{|c|c|c|}
\hline Judul & Penulis (Tahun) & $\begin{array}{c}\text { Strategi peningkatan } \\
\text { objektivitas hasil inspeksi } \\
\text { visual }\end{array}$ \\
\hline $\begin{array}{l}\text { Japanese Pharmacopeia (JP) } \\
\text { and United } \\
\text { Pharmacopeia States } \\
\text { developments in visual } \\
\text { inspection for foreign } \\
\text { particulate matter. }\end{array}$ & Shabushnig et al. (2015) [9] & $\begin{array}{l}\text { Pelaksanaan inspeksi visual } \\
\text { dilakukan dengan } \\
\text { memperhatikan beberapa } \\
\text { faktor tertentu seperti cahaya, } \\
\text { waktu dan kecepatan uji serta } \\
\text { pergerakan sampel. }\end{array}$ \\
\hline $\begin{array}{l}\text { How and why we need to } \\
\text { capture tacit knowledge in } \\
\text { manufacturing: Case studies } \\
\text { of visual inspection. }\end{array}$ & Johnson et al. (2019) [10] & $\begin{array}{l}\text { Menggunakan serangkaian } \\
\text { metode khusus yang } \\
\text { bertujuan untuk } \\
\text { mengoptimalkan keakuratan } \\
\text { keputusan lulus / gagal yang } \\
\text { dibuat selama inspeksi visual. }\end{array}$ \\
\hline $\begin{array}{l}\text { A survey of industry practice } \\
\text { for the visual inspection of } \\
\text { injectable products }\end{array}$ & Leversee et al. (2008) [11] & $\begin{array}{l}\text { Untuk mempertahankan } \\
\text { keakuratan uji diperlukan } \\
\text { resertifikasi dan rekualifikasi } \\
\text { secara berkala untuk operator } \\
\text { yang melakukan uji inspeksi } \\
\text { visual }\end{array}$ \\
\hline $\begin{array}{l}\text { Effect of inspection } \\
\text { performance in smart } \\
\text { manufacturing systembased } \\
\text { on human quality control } \\
\text { system. }\end{array}$ & Kang et al. (2018) [12] & $\begin{array}{l}\text { Jumlah operator pada inspeksi } \\
\text { visual mempengaruhi secara } \\
\text { signifikan kinerja inspeksi. }\end{array}$ \\
\hline
\end{tabular}


Pelaksanaan inspeksi visual dan hasilnya dapat dipengaruhi beberapa faktor yaitu kontras antar cacat dan latar belakang item, pencahayaan, waktu dan kecepatan uji, serta pergerakan sampel. Faktor tersebut jika dipenuhi sesuai persyaratan yang ditentukan pada saat uji dapat memudahkan seorang operator dalam mendeteksi adanya partikel dalam sediaan ${ }^{9}$.

Serangkaian metode yang bertujuan untuk mengoptimalkan keakuratan keputusan lulus I gagal yang dibuat selama inspeksi visual telah dilakukan. Metode tersebut dimulai dengan analisis bagan pareto yang cacat penentuan spesifikasi cacat, evaluasi kinerja, hingga sertifikasi operator ${ }^{10}$. Penelitian sebelumnya menjelaskan bahwa peningkatan usia dapat mempengaruhi kemampuan seseorang dalam melaksanakan uji inspeksi visual, sehingga diperlukan resertifikasi dan rekualifikasi ulang untuk operator agar menjamin keakuratan dari hasil $\mathrm{uji}^{11}$.

Jumlah operator pada pelaksanaan uji inspeksi visual berpengaruh secara signifikan terhadap kinerja inspeksi, dengan melibatkan gabungan dua atau lebih operator yang memiliki tingkat kemampuan berbeda dalam mendeteksi cacat, sehingga diharapkan dalam proses inspeksi terdapat kesepakatan antar operator terkait hal - hal yang dibutuhkan untuk memberikan hasil uji yang akurat ${ }^{12}$.

\section{Pembahasan}

Regulasi dunia mempersyaratkan $100 \%$ inspeksi visual untuk produk parenteral terhadap adanya cemaran partikel asing. United States Pharmacopeia (USP) menggunakan terminologi "essentially free", bahwa tidak ada sejumlah unit partikulat yang ditemukan melebihi batas maksimal yang telah ditentukan pada produk injeksi yang diperiksa. Sedangkan European Pharmacopeia (EP) menggunakan terminologi "Practically free" of visible particles, dan Japanese Pharmacopoeia (JP) menggunakan terminologi 'free from readily detectable foreign insoluble matters' ${ }^{13}$.

Inspeksi visual manual merupakan metode yang digunakan dalam pemeriksaan partikulat. Inspeksi ini dilakukan di bawah kondisi terkendali dengan melihat isi kemasan tertutup. Pelaksanaan inspeksi visual dilakukan oleh seorang operator dimana seorang operator menentukan tingkat kualitas dan keberhasilan dari proses inspeksi visual. Sebagai standar minimum seorang operator harus memiliki pengelihatan yang baik, teliti, tidak buta warna, serta terlatih ${ }^{13}, 14$.

Beberapa faktor yang berpengaruh terhadap pelaksanaan inspeksi visual dan hasilnya yaitu :

1. Kontras antara cacat yang terdeteksi dan latar belakang item

Telah dipersyaratkan dalam semua Farmakope untuk inspeksi digunakan latar belakang hitam dan putih. Latar belakang hitam dan putih mampu memberikan kontras yang dapat membantu mata untuk mendeteksi partikel dan kecacatan kemasan. Peningkatan kontras akan membuat mata dapat lebih sensitif dalam melihat partikulat, sehingga lebih mudah untuk membedakan dan meningkatkan probabilitas cacat yang dapat terdeteksi. Direkomendasikan untuk penggunaan latar belakang yang tidak mengkilap agar menghindari pantulan yang dapat mengganggu pengamatan ${ }^{4}$. 


\section{Pencahayaan pada saat proses deteksi}

Untuk dapat melihat suatu objek diperlukan sumber cahaya oleh mata. Lampu fluoresens sering digunakan sebagai sumber cahaya, selain itu dapat digunakan pula lampu pijar, dan LED. Pencahayaan yang digunakan merupakan cahaya baur tidak langsung (diffuse). Pencahayaan umumnya dilakukan dari arah atas obyek yang diinspeksi. Diperlukan pencahayaan melewati isi wadah dari arah bawah untuk beberapa kasus tertentu. Misalnya, untuk larutan atau wadah yang berwarna kuat. Pencahayaan dari belakang dengan melewati wadah dapat dilakukan untuk inspeksi produk dengan wadah kantung yang fleksibel ${ }^{4}$.

USP dan EP merekomendasikan tingkat pencahayaan pada titik inspeksi dalam rentang 2.000-3.750 lux cahaya putih untuk wadah gelas bening. Sedangkan wadah plastik buram atau gelas amber dapat digunakan peningkatan hingga 10.000 lux [4].

Untuk pemastian pemenuhan persyaratan intesitas pencahayaan secara berkala harus diukur. Data pengalaman penggunaan jenis lampu yang digunakan dapat dijadikan dasar dalam menentukan frekuensi pemantauan. Frekuensi ini dapat dilakukan mingguan atau dalam interval lebih panjang. Selama sistem pencahayaan masih stabil, pemantauan selama proses inspeksi atau harian tidak diperlukan. Namun, diperlukan penetapan batas terendah intensitas pencahayaan untuk memastikan intensitas pencahayaan yang digunakan, contoh $+10 \%$ dari batas terendah kompendial harus ditetapkan untuk dilakukan tindakan koreksi sebelum inspeksi dijalankan di bawah batas rentang [7].

\section{Waktu dan kecepatan pada saat pemeriksaan}

USP merekomendasikan durasi inspeksi untuk setiap wadah yang adalah 10 detik, dengan latar belakang hitam dan putih masing-masing 5 detik. Waktu yang lebih lama dapat digunakan untuk kemasan yang lebih besar atau lebih kompleks. Waktu yang ditetapkan untuk mengamati suatu obyek akan berdampak pada sensitivitas proses inspeksi, pencarian detail masalah dan waktu keputusan diterima atau ditolak merupakan bagian penting yang harus ditetapkan ${ }^{15}$.

\section{Pergerakan sampel}

Pergerakan obyek dalam melakukan proses inspeksi visual dimulai dengan kondisi awal diam, pembalikan, dan penggoyangan. Ada atau tidaknya partikel kasar pada latar belakang putih merupakan pengamatan yang dilakukan di awal dengan melihat partikel yang mungkin terendap di dasar kemasan, selanjutnya, kemasan dibalik agar partikel baik yang mungkin terendap di dasar ataupun yang menempel pada kemasan dapat terbawa oleh aliran air. Untuk membuat partikel halus bergerak kemasan dimiringkan hingga membentuk sudut $45^{\circ}$ dan digoyang perlahan. Dalam pergerakan kemasan perlu diperhatikan gelembung udara yang mungkin terbentuk. Munculnya gelembung dapat menyebabkan jumlah unit yang ditolak secara keliru meningkat karena gelembung dan partikel sulit dibedakan. Dalam tiap urutan ini, kemasan dari dasar ke atas diamati untuk dapat mendeteksi dini partikel kasar dan memberikan kesempatan gelembung naik. Kecacatan kemasan juga perlu diperiksa untuk mendeteksi adanya retakan, kebocoran, atau penutupan yang tidak tepat. Kemudian urutan tersebut diulangi hingga semua tahap inspeksi selesai dengan menggunakan latar belakang hitam $^{15}$. 
Terdapat beberapa hal lain yang dapat mempengaruhi hasil inspeksi visual terhadap sediaan. Jumlah operator yang melakukan uji inspeksi visual dapat mempengaruhi secara signifikan kinerja inspeksi, dengan melibatkan operator yang memiliki kemampuan sangat baik dalam mendeteksi cacat dan operator yang memiliki kemampuan kurang baik dalam mendeteksi cacat. Hal ini dapat memicu peningkatan kemampuan dari operator yang memiliki kemampuan kurang baik dalam mendeteksi cacat, karena diharapkan dalam proses inspeksi terdapat kesepakatan antar operator terkait hal - hal apa saja yang dibutuhkan untuk memberikan hasil uji yang akurat. Kemampuan seorang operator dapat diukur dari kemampuannya mendeteksi kecacatan dari adanya partikel dalam sediaan pada saat kualifikasi awal operator serta pengalaman dalam melakukan inspeksi visual ${ }^{12}$.

Peningkatan keakuratan keputusan lulus / gagal yang dibuat pada inspeksi visual dapat juga dilakukan dengan menerapkan serangkaian metode khusus, sehingga akan meningkatkan kualitas dari suatu produk yang mana pada umumnya diabaikan [10]. Metode ini tidak dirancang untuk mengatasi faktor-faktor yang mempengaruhi cacat pada saat deteksi, seperti waktu yang diizinkan untuk inspeksi, keterampilan dan pengalaman operator, atau visibilitas cacat, tujuan utama adalah untuk mengoptimalkan keakuratan keputusan lulus / gagal yang dibuat selama inspeksi visual. Metode tersebut terdiri dari tahapan:

\section{a. Analisis bagan pareto yang cacat}

Pembuatan bagan pareto berdasarkan frekuensi dan persentase serta jumlah kumulatif cacat, kemudian melakukan survei sederhana terhadap operator untuk menentukan cacat mana yang paling sulit untuk dievaluasi dan karena itu paling membutuhkan perhatian. Apapun pendekatan yang digunakan, langkah pertama adalah mengidentifikasi cacat yang signifikan dan sering terjadi ${ }^{10}$.

Analisis Pareto dapat digunakan untuk membandingkan jumlah unit yang rusak pada setiap jenis cacat. Bagan ini memungkinkan operator untuk memprioritaskan cacat berdasarkan frekuensinya ${ }^{16}$.

\section{b. Persetujuan spesifikasi cacat}

Meminta pemangku kepentingan utama, kualitas, produksi dan pelanggan untuk menyepakati definisi dan spesifikasi untuk cacat yang dipilih. Berdasarkan spesifikasi yang akan dilakukan dalam proses atau pada persyaratan produk akhir. Semua yang berkepentingan sebagai pemangku kebijakan harus mencapai kesepakatan tentang definisi cacat dan batas yang diterima sehingga tingkat cacat yang dapat diterima dan tidak dapat diterima bisa ditentukan sebelum operator dapat bekerja dengan spesifikasi tersebut. Dapat dilakukan dengan cara menunjukkan contoh dari salah satu standar untuk tanda identitas. Dengan mendokumentasikan cacat dengan contoh foto dan deskripsi teknis, menetapkan kriteria yang jelas dan konsisten bagi operator untuk membuat keputusan lulus/gagal ${ }^{10}$. 
c. Evaluasi Kinerja Inspeksi saat ini menggunakan Attribute Agreement Analysis Penelitian ini memberikan informasi tentang konsistensi keputusan lulus / gagal dari operator. Untuk melakukan penelitian, mintalah sekelompok operator yang representatif mengevaluasi sekitar 30 hingga 40 cacat visual dan ulangi, kemudian evaluasi mereka setidaknya satu kali. Dari penelitian ini, dapat dinilai mengenai konsistensi keputusan antar operator dan menentukan seberapa baik keputusan operator tersebut sesuai dengan standar yang diketahui atau respons yang benar untuk setiap bagian ${ }^{10}$.

\section{d. Komunikasikan hasil kepada Operator-per bagian}

Hasil penelitian diatas disampaikan kepada operator dengan jelas dan objektif, yang menunjukkan jenis perbaikan apa yang dibutuhkan. Matriks ini menunjukkan penilaian operator untuk 20 bagian, dengan kode warna untuk menunjukkan respons yang benar dan salah. Jika seorang operator lulus dan gagal pada bagian yang sama, maka respons yang salah ditampilkan. Matriks juga menunjukkan jenis respons yang salah menolak bagian yang dapat diterima atau melewati bagian yang tidak dapat diterima ${ }^{10}$.

Matriks operator per bagian dengan jelas mengomunikasikan kinerja keseluruhan dari proses inspeksi. Setiap operator dapat dengan mudah membandingkan tanggapannya dengan operator lain untuk menilai kinerja relatif. Dengan juga mempertimbangkan kemampuan masing-masing operator untuk mencocokkan penilaian untuk bagian yang sama $^{10}$.

Matriks ini dapat digunakan untuk menentukan apakah respons yang salah disebabkan oleh ketidakpastian tentang cacat (kesepakatan mandiri rendah) atau konsisten penggunaan kriteria yang salah (kesepakatan rendah dengan orang lain). Jika banyak respons yang salah terjadi di kolom sampel yang sama, tingkat cacat atau cacat itu mungkin tidak memiliki respons standar yang jelas. Secara potensial, pengawas tidak menyepakati definisi atau spesifikasi yang jelas untuk cacat dan mungkin memerlukan pelatihan lebih lanjut untuk menyepakati tingkat keparahan untuk penolakan ${ }^{10,17}$.

\section{e. Evaluasi kembali proses}

Selanjutnya memberikan pelatihan baru sesuai dengan kebutuhan, evaluasi ulang proses inspeksi dengan mengulangi tahapan ketiga yaitu melakukan evaluasi kinerja awal dan tahapan keempat yaitu komunikasikan kembali hasil kepada operator-per bagian. Dalam mengukur peningkatan kualitas operator pada proses inspeksi dapat digunakan analisis statistik yang akan mencocokkan hasil inspeksi operator dengan jawaban benarnya. Nilai ini akan menentukan sejauh mana ketelitian operator dalam melakukan inspeksi visual ${ }^{10}$.

\section{f. Menerapkan program sertifikasi operator}

Untuk mempertahankan tingkat akurasi inspeksi yang tinggi, langkah terakhir dalam meningkatkan inspeksi visual adalah dengan menerapkan sertifikasi dan / atau program audit. Jika tidak ada program semacam itu yang diterapkan, kinerja inspeksi dapat kembali ke level semula ${ }^{10}$. Kemudian, penerapan rekualifikasi dan resertifikasi operator harus secara berkala dilakukan sehingga dapat diketahui kemungkinan adanya penurunan kemampuan deteksi dalam uji visual inspeksi yang dapat dipengaruhi oleh usia ataupun faktor lainnya ${ }^{11}$. 


\section{Kesimpulan}

Peningkatan objektivitas hasil uji inspeksi visual dapat dilakukan dengan memperhatikan parameter-parameter pengujian seperti kontras background, cahaya, pergerakan partikel, waktu dan kecepatan inspeksi, waktu istirahat operator, serta jumlah operator. Selain itu untuk mengoptimalkan keakuratan keputusan lulus/gagal dari hasil inspeksi dapat dilakukan dengan membuat analisis bagan, dilanjutkan dengan penentuan spesifikasi cacat, evaluasi kinerja, hingga sertifikasi operator.

\section{Daftar Pustaka}

1. Duffuaa SO, Khan M. Impact of inspection errors on the performance measures of a general repeat inspection plan. Int J Prod Res. 2005; 43(23):4945-4967.

2. Depkes RI. Farmakope Indonesia, Edisi IV. Jakarta: Departemen Kesehatan Republik Indonesia; 1995.

3. Bukofzer, S., Ayers, J. Industry Perspective on the Medical Risk of Visible Particles in Injectable Drug Products. PDA J.Pharm. Sci. Technol. 2015; 69(1):123-139.

4. Shabushnig JG. Hot Topics in Visual Inspection on a Cold January Night. LLC: Insight Pharma Consulting; 2015.

5. openFDA database. recall enforcement reports. [diakses pada 21 November 2019]. Tersedia dari: https://open.fda.gov

6. Charles, R. L., T. L Johnson., S.R. Fletcher. The use of Job Aids for Visual Inspection in Manufacturing and Maintenance. Procedia CIRP. 2015; 38: 90 - 93.

7. Aldrich DS, Cherris RT, Shabushing JG. Visual Inspection and Particulate Control. Bethesda: Parenteral Drug Association; 2016.

8. Melchore JA. "Lessons learned regarding particulate inspection," Presentation at PDA metro chapter. PDA:Somerset NJ; 2007.

9. Shabushnig JG, Katayama H. Japanese Pharmacopeia (JP) and United States Pharmacopeia (USP) developments in visual inspection for foreign particulate matter. PDA Journal of GMP and Validation in Japan. 2019;17(1): 94-103.

10. T.L., Johnson, S.R Fletcher, W. Baker, R.L., Charles. How and why we need to capture tacit knowledge in manufacturing: Case studies of visual inspection. Bedford: Industrial Psychology and Human Factors Group, School of Aerospace, Transport and Manufacturing, Cranfield University; 2019.

11. Leversee, RL., JG, Shabushing. A survey of industry practice for the visual inspection of injectable products. PDA Preliminary Report; 2008.

12. Kang H W, Babar R, Biswajit S, Imran M. Effect of inspection performance in smart manufacturing systembased on human quality control system. The International Journal of Advanced Manufacturing Technology. 2018; 94(9): 4351-4364.

13. Das, Tapan. Industry Perspective On The Control Of Visible Particles. Europe: Biologics Development, Bristol-Myers Squibb European Biopharmaceutical Enterprises(EBE) satellite Session CMC Strategy Forum Europe; 2017.

14. Mathonet S, Mahler HC, Esswein ST, Mazaheri M, Cash PW, Wuchner K, et al. A Biopharmaceutical Industry Perspective on the Control of Visible Particles in Biotechnology-Derived Injectable Drug Products. PDA J Pharm Sci Technol. 2016; 70(4):392-408. 
15. USP 40-NF 35 Supplement 1. General Information <1790> Visual Inspection of Injection. Rockville: The United States Pharmacopeial Convention; 2017.

16. Rathore, Nitin., Chen, C., Gonzalez, O., Ji, W. Challenges and Strategies For Implementing Automated Visual Inspection For Biopharmaceuticals. Pharmaceutical Technology Injectables. 2009; 33(11): 25.

17. Clemons, J, A. Training Methods For Visual Inspection Tasks. Ames: Lowa State University; 2013. 